\title{
Allelopathic Effects of Water Extracts of Maize Leaf on Three Chinese Herbal Medicinal Plants
}

\author{
Xiaobang PENG \\ Shangluo University, College of Biopharmaceutical and Food Engineering, Shangluo, Shaanxi 726000, China; pengxiaobang6@163.com
}

\begin{abstract}
Plants generate various secondary metabolites named as allelochemicals that can be release into the environment and influence the growth and development of other plants or the same plant. The potential allelopathic effect of maize (Zea mays L.) on seed germination, seedling growth and physiology was investigated with three medicinal plants (Platycodon grandiflorum A.DC, Scutellaria baicalensis Georgi and Salvia miltiorrhiza Bge) with different concentrations (0, 0.5\%, 1.0\%, $2.5 \%, 5.0 \%, 10.0 \%)$. Low concentrations $(0.5 \%, 1.0 \%)$ of maize leaf aqueous extract stimulated the germination and seedling growth (root length, shoot height, fresh weight) of all receptor plants significantly. With the concentration of the aqueous extract increased, the stimulating effects gradually decreased, and even changed into inhibited. The aqueous leachate of maize leaves exerted different allelopathic effects on physiology of different test medicinal plants. For Platycodon grandiflorum A.DC, there was no significant difference in photosynthesis rate at all the tested concentration compared with control. In Scutellaria baicalensis Georgi the lower concentration $(0.5 \%, 1.0 \%, 2.5 \%)$ of leachates stimulated the net photosynthesis rate, yet the higher concentration $(5.0 \%, 10.0 \%)$ decreased the net photosynthesis rate, and all the tested concentration have inhibited effects on Salvia miltiorrhiza Bge and decreased its net photosynthesis rate. However, the content of soluble sugar and soluble protein of all receptor plants were stimulated by low concentrations $(0.5 \%, 1.0 \%, 2.5 \%)$ of maize leaf aqueous extract. Allelopathy can affect the seed germination, early seedling growth and physiology of three medicinal plants.
\end{abstract}

Keywords: allelopathic; maize leaves leachate; Platycodon grandiflorum A.DC; Salvia miltiorrhiza Bge; Scutellaria baicalensis Georgi

\section{Introduction}

Allelopathy is defined as the direct or indirect harmful or beneficial effects of one plant on another through the production and release of secondary metabolites into the environment (Machado, 2007; Baziar et al., 2014). The secondary metabolites exhibiting allelopathic potential are called as allelochemicals, which can be produced by plants that interact with the surrounding environment by influencing the growth and development of neighboring plants (Liu et al., 2016; Sitthinoi et al., 2017). Allelopathy plays a significant role in regulating the growth and development of agricultural and biological systems, including quality and quantity of crops (Kohli et al., 1997; Singh et al., 2001; Baziar et al., 2014). Although allelochemicals can be produced by all plant parts, but the leaves and roots are mainly responsible for their production and release (Hou et al., 2016; Gulzar et al., 2017). For the past several years, many researchers have done much work of allelopathy using plants leaf aqueous extract (Jefferson and
Pennacchio, 2003; Dorning and Cipollini, 2006; Hou et al., 2016; Gulzar et al., 2017), and the results showed that this method was still the most efficiency approach for allelopathic effects research.

China is one of using-medical-plant countries with a long history, medical plants are source of important therapeutic aid for alleviating human aliments. Approximately $80 \%$ of the people in the world's developing countries rely on traditional medicine for their primary health care needs, and $85 \%$ of traditional medicine involves the use of plant extracts (Vieira and Skorupa, 1993). Platycodon grandiflorum A.DC, Scutellaria baicalensis Georgi and Salvia miltiorrhiza Bge are traditional medicinal plants and applied widely in China for a long time, and they are also as unique Chinese herbal medicine and widely cultivated in Shangluo, Shaanxi. They are famous for the immunomodulating effects and treatment of colds cough, celiac diarrhea, coronary heart disease and cerebrovascular disease. At present, many farmers in China begin to cultivate them because of shortage of wild resource. 
However, the high-efficiency monoculture has caused new problems, which buildup of pests and soil sickness, severely deteriorated soil health, and the yields of medicinal plants decreased year by year (Gao et al., 2006). This is what we say the continuous cropping obstacles. Therefore, the recent emphasis in Chinese herbal medicine planting has shifted from a primary goal of maximizing yields over the short term, to a sustainable productivity over long periods of time. In the actual production, it was reported that Chinese herbal medicine plants rotation with corn can overcome this obstacle and obtain high yields of herbal medicine (Fabricant and Farnsworth, 2001; Yuan et al., 2016). Therefore, it is important to select the properly species for crop rotations or intercropping, and if these effects are utilized properly, the continuous cropping obstacles problem could be overcome through the adoption of crop rotations and intercropping systems, it is possible to speed up the development of ecological sustainable agriculture. However, no such research has been done on the effects of aqueous extracts of maize leaves on medicinal plants in China. Bioassays are useful and necessary tools for studying the allelopathic potential of plant extracts and for evaluating the activity of the extracts during purification and identification of allelopathic compounds (Hou et al., 2016). Therefore, the aim of this work was to study the allelopathic effects of maize leaves on the seed germination, early seedling growth and physiology of three medicinal plants, in order to get some useful information for maize rotations or intercropping with these three medicinal plants.

\section{Materials and Methods}

Preparation of aqueous extracts

The fresh leaves of maize (Zea mays L.) were collected in September 2011, from the experimental field, Department of Biological and Medical Engineering, Shangluo University, Shangluo, Shaanxi, China. Fresh leaves were cut into $1-\mathrm{cm}$ pieces and $10 \mathrm{~g}$ fresh sample were immersed in $100 \mathrm{ml}$ distilled water and shaken for $24 \mathrm{~h}$ at room temperature $\left(20-25^{\circ} \mathrm{C}\right)$, the solution was filtered through three-layers of filter paper and kept at $4{ }^{\circ} \mathrm{C}$ until application. For germination bioassay, it was further diluted to $0 \%$, $0.5 \%, 1.0 \%, 2.5 \%, 5.0 \%, 10.0 \%$ concentrations with distilled water.

\section{Germination bioassay}

All seeds of three receptor plants (Platycodon grandiflorum A.DC, Scutellaria baicalensis Georgi, and Salvia miltiorrhiza Bge) were purchased from the Medicinal materials market of Shangluo, Shaanxi, China. Before germination tests, the plant seeds were surface-sterilized with 10:1 water/bleach (commercial $\mathrm{NaOCl}$ ) solution for 5 $\mathrm{min}$ and then washed six times with distilled water ( $\mathrm{Li}$ et al., 2010b).

Seeds of three receptor plants were germinated and the filter paper was moistened with $5 \mathrm{~mL}$ of the aqueous extracts of $0.5 \%, 1.0 \%, 2.5 \%, 5.0 \%, 10.0 \%$, and distilled water was used as control. Twenty seeds were spread out on two sheets of filter paper placed in Petri dishes $(9 \mathrm{~cm}$ diameter). There were five replicate Petri dishes for each treatment. The Petri dishes were randomized and incubated at $25^{\circ} \mathrm{C}$ in darkness in an incubator. Germination was determined by counting the number of germinated seeds at $24 \mathrm{~h}$ till 10 days. The germination rate $(G R)$ was calculated as follows: $G R(\%)=$ seeds germinated / total seeds $\times 100$. The germination index $(G I)$ was calculated using the formula $G I=\Sigma G_{i} / T_{i}$, where $G_{i}$ is the number of radicles emerged at time $i$, and $T_{i}$ is the number of days from planting. The inhibitory rate $(I R)$ was calculated using the formula $(C-T) / C \times 100 \%$, where $C$ is the mean value of control, and $T$ is the mean value of each extract treatment. $I R>0$ indicates inhibition, $I R<0$ indicates promotion, and the magnitude of $I R$ values reflects the intensity of the allelopathic effect (Williamson and Richardson, 1988). At the same time, by referring to Read and Northcote (1981), soluble protein $(S P)$ and soluble sugar $(S S)$ of receptor were tested everyday. After 10 days incubation, the receptor plants germination in each dish was recorded, the length of root, shoot and fresh weight of the plants were measured. Final germination was expressed as percentage after statistical analyses were performed on the raw data.

\section{Pot culture}

Plastic pots (each $15 \times 10 \mathrm{~cm}$ ) were filled with $500 \mathrm{~g}$ of vermiculite and five seedlings (14-days old) of Platycodon grandiflorum A.DC, Scutellaria baicalensis Georgi and Salvia miltiorrhiza Bge were transplanted in each pot. The pots were watered daily with $100 \mathrm{ml}$ fresh leaves leachate of $0.5 \%, 1.0 \%, 2.5 \%, 5.0 \%, 10.0 \%$ concentration as per treatments, and $100 \mathrm{~mL}$ distilled water was used as control at the same time. The pots were kept in a greenhouse with 12 hours day length and day and night temperatures of 24 and $18{ }^{\circ} \mathrm{C}$ respectively. There were five replicates for each treatment, and the pots were completely randomized.

After two weeks, a portable photosynthesis system (LI6400; LI-COR Inc., Lincoln, NE, USA) with a red/blue LED light source (LI6400-02B) mounted onto a $6 \mathrm{~cm}^{2}$ chamber was used to determine the rate of net $\mathrm{CO}_{2}$ assimilation (NA). Each treatment was repeated three times.

\section{Statistical analysis}

All the data were analyzed using a one-way ANOVA test in the statistical software SPSS 12.0.1, and means were compared using Duncan's multiple range test at 5\% level.

\section{Results}

Germination rate of three medicinal plants in different concentrations of maize leaf aqueous extract

As shown in Table 1, the low concentrations of maize leaf aqueous extract stimulated the rate of the three medicinal plants seed germination significantly, when the concentrations of maize leaf aqueous extract reached 1.0\%, Platycodon grandiflorum A.DC and Salvia miltiorrhiza Bge reached the highest germination rate. However, the highest germination rate of Scutellaria baicalensis Georgi was appeared at the concentrations of $5.0 \%$ (Table 1). With the concentration of the aqueous extract increased, the germination rate of all the receptors decreased, and the 
196

lowest germination rate of three medicinal plants seed were all appeared at the highest concentrations of maize leaf aqueous extract (10.0\%). The results showed that low concentrations of maize leaf aqueous extract stimulated the rate of seed germination of the three medicinal plants, and high concentration of the aqueous extract could have an inhibitory effect on seed germination of the three medical plants.

Germination index of three medicinal plants in different concentrations of maize leaf aqueous extract

The germination index $(G I)$ of the three medicinal plants at different concentrations of maize leaf aqueous extract was present in Table 2. The main factors and interactions appeared significant in the statistical analysis. Increasing proportion of maize leaf aqueous extract reduced the germination index of Scutellaria baicalensis Georgi and Salvia miltiorrbiza Bge, and a considerable decrease in germination index was recorded when maize leaf aqueous extract concentration exceeded $2.5 \%$. In Platycodon grandiflorum A.DC this "threshold value" appeared from $1.0 \%$ concentration of maize leaf aqueous extract. The biggest germination index of Scutellaria baicalensis Georgi and Salvia miltiorrhiza Bge were appeared at the concentrations of maize leaf aqueous extract reached $1.0 \%$, while the biggest one of Platycodon grandiflorum A.DC was at $0.5 \%$ concentrations of maize leaf aqueous extract.

\section{Seedling growth of three medicinal plants in different} concentrations of maize leaf aqueous extract

The effects of different concentrations of maize leaf aqueous extract on root length of three receptors are shown in Fig. 1A. The low concentration of maize leaves aqueous extracts significantly stimulated the root length of all the tested medicinal plants, Scutellaria baicalensis Georgi was affected most strongly, with stimulation of radicle elongation by all $2.5 \%$ range of the aqueous extracts, and the highest stimulation of all receptor plants was in Scutellaria baicalensis Georgi at 2.5\% concentration (root length increased $30.1 \%$ compared with control). However, with the concentration increasing, the effects of aqueous extracts of maize leaves began to inhibit the radicle elongation, even start from 1.0\% concentration for Salvia miltiorrhiza Bge. The effects on shoot height was similar with it on root length (Fig. 1B), which was low concentrations stimulated the shoot height of the medical plants and high concentration inhibited it. The shoot height of Platycodon grandiflorum A.DC and Salvia miltiorrhiza Bge were inhibited at $5.0 \%$ and $2.5 \%$ concentration respectively, and at $10.0 \%$ concentration, the highest inhibition was in Salvia miltiorrhiza Bge (shoot height decreased $46.1 \%$ compared with control). On the other hand, the shoot height of Scutellaria baicalensis Georgi was similar to root length of it, which was promoted by $18.3 \%$ at $2.5 \%$ concentration. Different allelopathic activities of seedlings fresh weight of three receptor plants at different concentrations showed various trends (Fig. 1C). For Scutellaria baicalensis Georgi and Salvia miltiorrhiza Bge, lower concentration (0.5\%, $1.0 \%, 2.5 \%)$ stimulated the seedling fresh weight, and higher concentrations $(5.0 \%$ and $10.0 \%)$ inhibited the fresh weight. At $10.0 \%$ concentration, the highest inhibition was in Salvia miltiorrbiza Bge (Fresh weight decreased 34.5\% compare with control). However, the different concentration of maize leaves leachate were harmless to fresh weight in Platycodon grandiflorum A.DC. In this experiment, Scutellaria baicalensis Georgi was the more promoted test species, while shoot height was the most sensitive parameter. The variance analysis showed significant interaction in germination rate, root length, shoot height and fresh weight between different test concentrations. In addition, we also found that the inhibition of maize leaves leachate to receptor plant's root growth not only appeared on the length of root but also on the form and color of root.

Table 1. Germination rate of three receptor plants in different concentrations of extracts

\begin{tabular}{cccc}
\hline Extracts concentration & Platycodongrandiflorum & Scutellaria baicalensis & Salvia miltiorrhiza \\
\hline $0 \%(\mathrm{CK})$ & $88.1 \pm 0.2 \mathrm{~b}$ & $80.1 \pm 0.6 \mathrm{~b}$ & $83.0 \pm 1.0 \mathrm{~b}$ \\
$0.5 \%$ & $90.8 \pm 0.8 \mathrm{a}$ & $82.1 \pm 0.1 \mathrm{~b}$ & $85.8 \pm 0.6 \mathrm{a}$ \\
$1.0 \%$ & $92.8 \pm 1.1 \mathrm{a}$ & $84.4 \pm 1.1 \mathrm{a}$ & $87.6 \pm 0.9 \mathrm{a}$ \\
$2.5 \%$ & $85.0 \pm 1.3 \mathrm{~b}$ & $85.2 \pm 0.2 \mathrm{a}$ & $81.0 \pm 0.6 \mathrm{~b}$ \\
$5.0 \%$ & $83.1 \pm 0.7 \mathrm{~b}$ & $87.1 \pm 0.2 \mathrm{a}$ & $80.1 \pm 0.9 \mathrm{~b}$ \\
$10.0 \%$ & $80.0 \pm 0.1 \mathrm{c}$ & $77.0 \pm 0.7 \mathrm{c}$ & $76.4 \pm 0.3 \mathrm{c}$ \\
\hline
\end{tabular}

Note: Different letters in the same column indicate significantly difference at the 0.05 level.

Table 2. Germination index of three receptor plants in different concentrations of extracts

\begin{tabular}{cccc}
\hline Extracts concentration & Platycodon grandiflorum $(\%)$ & Scutellaria baicalensis $(\%)$ & Salvia miltiorrhiza $(\%)$ \\
\hline $0 \%(\mathrm{CK})$ & $3.6 \pm 0.4 \mathrm{a}$ & $2.7 \pm 0.3 \mathrm{~b}$ & \\
$0.5 \%$ & $4.0 \pm 0.4 \mathrm{a}$ & $3.0 \pm 0.4 \mathrm{a}$ & \\
$1.0 \%$ & $3.3 \pm 0.6 \mathrm{~b}$ & $3.2 \pm 0.5 \mathrm{a}$ & \\
$2.5 \%$ & $3.2 \pm 0.3 \mathrm{~b}$ & $2.6 \pm 0.8 \mathrm{~b}$ & \\
$5.0 \%$ & $2.9 \pm 0.6 \mathrm{~b}$ & $2.0 \pm 0.5 \mathrm{c}$ & \\
$10.0 \%$ & $2.3 \pm 0.7 \mathrm{c}$ & $2.0 \pm 0.7 \mathrm{c}$ & $3.72 \pm 0.8 \mathrm{~b}$ \\
\hline
\end{tabular}

Note: Different letters in the same column indicate significantly difference at the 0.05 level. 
A

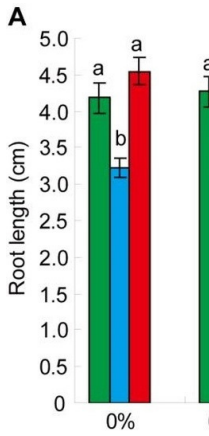

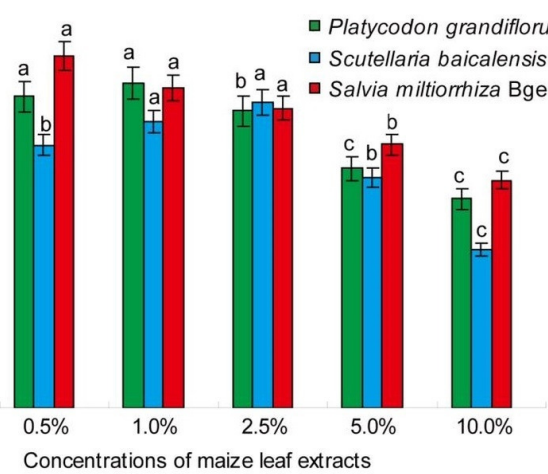

B

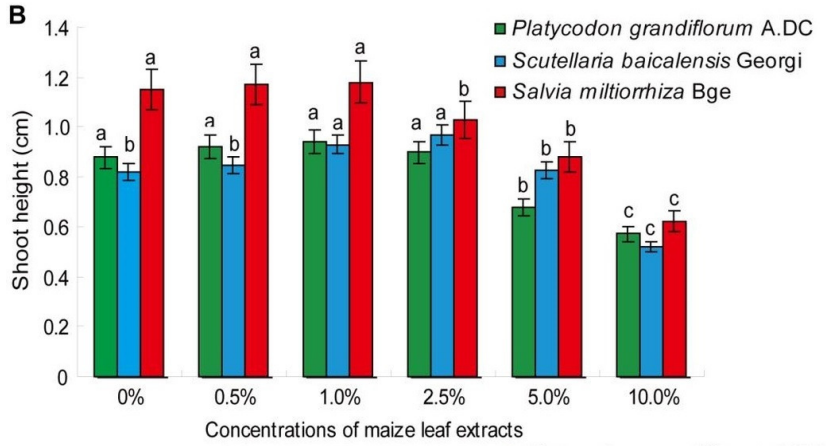

C 0.1

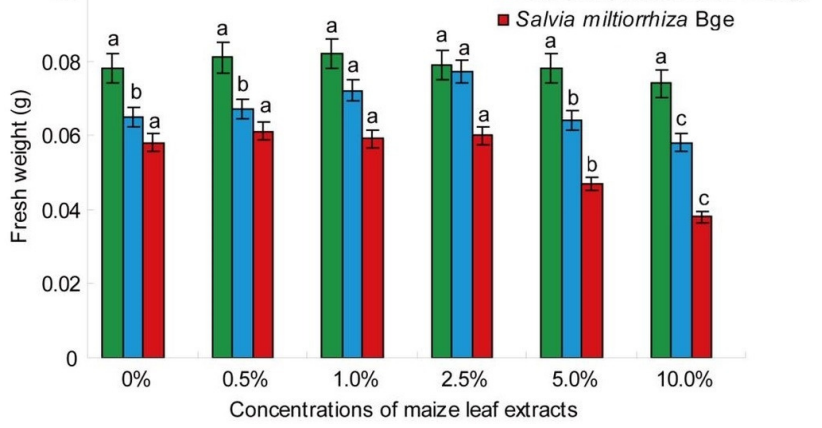

Fig. 1. The physiological parameters of three receptor plants in different concentrations of maize leaf aqueous extract. (A) Root length; (B) shoot height; (C) fresh weight

Effect of the soluble protein and soluble sugar content alteration of three medicinal plants in different concentrations of maize leaf aqueous extract

Soluble protein as important matter can provide nitrogen nutrient for seed germination and seedling growth, and it has significant relationship with formation and keep the seed vigor. Table 3 shows that soluble protein content increased continually at the stage of low concentrations $(0.5 \%, 1.0 \%, 2.5 \%)$ of maize leaf aqueous extract. When the concentrations continued to increase, especially starting from the $5.0 \%$ concentration, the soluble protein of three receptor plants decreased sharply. The lowest soluble protein content of Platycodon grandiflorum A.DC, Scutellaria baicalensis Georgi and Salvia miltiorrbiza Bge were all appeared in the highest concentration $(10 \%)$ in our experiment, and their soluble protein content decreased $12.6 \%, 9.9 \%$ and $25.7 \%$ respectively compared with the control. Soluble sugar as important osmoregulation matter can decrease osmotic potential and improve stability of soluble protein. As shown in Table 4, all aqueous leachate affected the soluble protein content of Platycodon grandiflorum A.DC, Scutellaria baicalensis Georgi and Salvia miltiorrhiza Bge. At the beginning of low concentrations $(0.5 \%, 1.0 \%)$, soluble sugar content of three receptor plants were increased unconspicuous, but it decreased significantly starting from the concentrations of $2.5 \%$, and the $10.0 \%$ leachate concentration caused the maximum inhibition in Platycodon grandiflorum A.DC (Soluble sugar content decreased $7.4 \%$ compare with control). It has been suggested that low concentrations of maize leaf aqueous extract can promote receptor plant seed's starch and storage protein mutual transformation, and provide energy and material base for seed germination and seedling growth.

Photosynthesis rate $(P n)$ of three medicinal plants in different concentrations of maize leaf aqueous extract

In our experiment, the photosynthesis rate of three receptor plants showed different variable trends induced by maize leaves leachate (Table 5). For Platycodon grandiflorum A.DC, there was no significant difference in photosynthesis rate at all the tested concentrations compared with control. In Scutellaria baicalensis Georgi the lower concentration $(0.5 \%, 1.0 \%, 2.5 \%)$ of leachates stimulated the net photosynthesis rate $(32.7 \%, 5.2 \%$, $44.1 \%)$, yet the higher concentration $(5.0 \%, 10.0 \%)$ decreased the net photosynthesis rate $(6.9 \%, 46.0 \%)$. However, as shown in Table 5, all the tested concentration have inhibited effects on Salvia miltiorrhiza Bge and decreased its net photosynthesis rate compared with control, and the lowest was at $10.0 \%$ concentration, the net photosynthesis rate decreased $50.5 \%$. These results showed the positive and negative mechanism of maize leaves leachate on various receptor plants at different concentration.

\section{Discussion}

It is well known that extensive work has been done on plant allelopathy which using plants organ aqueous extract (Jefferson and Pennacchio, 2003; Dorning and Cipollini, 2006; Gulzar et al., 2017; Sitthinoi et al., 2017). In the current study, low concentrations $(0.5 \%, 1.0 \%)$ of maize leaf aqueous extract stimulated the rate of seed germination significantly of the three receptors, for Scutellaria baicalensis Georgi, the effective concentration even up to $5.0 \%$. The results showed that low concentrations $(0.5 \%, 1.0 \%)$ of maize leaf aqueous extract enhanced the root length, shoot height and fresh weight of receptor plants, but with the concentration of the aqueous extract increased, the stimulating effects of all the receptors gradually decreased, and even changed into inhibited. It has been frequently suggested that the low concentrations of maize leaf aqueous extract stimulated the rate of seed germination and seedling growth of the three medicinal plants, and high concentration of the aqueous extract could have an inhibitory effect on that of the medical plants. It indicates that maize leaf aqueous extract liquid contains some of the hydrophilic allelochemicals which affect plant seed germination and seedling growth of the receptor, and they have some damage effect to cell membrane and enzyme activity (Baziar et al., 2014; Gulzar et al., 2017; Sitthinoi et al., 2017). 
198

Table 3. Content of soluble protein of three receptor plants in different concentrations of extracts

\begin{tabular}{cccc}
\hline Extracts concentration & Platycodon grandiflorum $(\mathrm{mg} / \mathrm{g})$ & Scutellaria baicalensis $(\mathrm{mg} / \mathrm{g})$ & Salvia miltiorrbiza $(\mathrm{mg} / \mathrm{g})$ \\
\hline $0 \%(\mathrm{CK})$ & $68.2 \pm 1.2 \mathrm{~b}$ & $55.2 \pm 1.1 \mathrm{~b}$ & $60.1 \pm 1.1 \mathrm{~b}$ \\
$0.5 \%$ & $71.1 \pm 0.6 \mathrm{a}$ & $58.3 \pm 1.0 \mathrm{~b}$ & $63.3 \pm 1.0 \mathrm{a}$ \\
$1.0 \%$ & $74.2 \pm 1.3 \mathrm{a}$ & $63.2 \pm 0.9 \mathrm{a}$ & $66.1 \pm 1.1 \mathrm{a}$ \\
$2.5 \%$ & $72.4 \pm 1.2 \mathrm{a}$ & $65.4 \pm 0.9 \mathrm{a}$ & $64.6 \pm 1.2 \mathrm{a}$ \\
$5.0 \%$ & $62.4 \pm 0.7 \mathrm{c}$ & $52.1 \pm 0.7 \mathrm{~b}$ & $50.2 \pm 0.6 \mathrm{c}$ \\
$10.0 \%$ & $59.6 \pm 0.6 \mathrm{c}$ & $49.8 \pm 1.1 \mathrm{c}$ & $44.7 \pm 1.3 \mathrm{c}$ \\
\hline
\end{tabular}

Note: Different letters in the same column indicate significantly difference at the 0.05 level.

Table 4. Content of soluble sugar of three receptor plants in different concentrations of extracts

\begin{tabular}{|c|c|c|c|}
\hline Extracts concentration & Platycodon grandiflorum (\%) & Scutellaria baicalensis (\%) & Salvia miltiorrhiza (\%) \\
\hline $0 \%(\mathrm{CK})$ & $12.4 \pm 1.0 \mathrm{~b}$ & $22.2 \pm 0.8 b$ & $14.4 \pm 1.1 \mathrm{~b}$ \\
\hline $0.5 \%$ & $12.7 \pm 0.8 \mathrm{a}$ & $22.7 \pm 0.6 \mathrm{a}$ & $14.9 \pm 0.2 \mathrm{a}$ \\
\hline $1.0 \%$ & $12.4 \pm 0.4 b$ & $22.7 \pm 0.7 \mathrm{a}$ & $14.5 \pm 0.8 b$ \\
\hline $2.5 \%$ & $12.5 \pm 1.1 \mathrm{a}$ & $21.9 \pm 0.9 \mathrm{~b}$ & $14.3 \pm 1.1 \mathrm{~b}$ \\
\hline $5.0 \%$ & $11.4 \pm 1.2 \mathrm{c}$ & $21.2 \pm 1.0 \mathrm{c}$ & $13.6 \pm 0.4 \mathrm{c}$ \\
\hline $10.0 \%$ & $11.3 \pm 0.9 \mathrm{c}$ & $21.2 \pm 0.7 \mathrm{c}$ & $12.8 \pm 0.3 \mathrm{c}$ \\
\hline
\end{tabular}

Table 5. Photosynthesis rate of three receptor plants in different concentrations of extracts

\begin{tabular}{cccc}
\hline Extracts concentration & Platycodon grandiflorum $\left(\mu \mathrm{mol} \cdot \mathrm{m}^{-2} \cdot \mathrm{s}^{-1}\right)$ & ${\text { Scutellaria baicalensis }\left(\mu \mathrm{mol} \cdot \mathrm{m}^{-2} \cdot \mathrm{s}^{-1}\right)}_{\text {Salvia miltiorrhiza }\left(\mu \mathrm{mol} \cdot \mathrm{m}^{-2} \cdot \mathrm{s}^{-1}\right)}$ \\
\hline $0 \%(\mathrm{CK})$ & $8.2 \pm 1.1 \mathrm{a}$ & $4.0 \pm 0.7 \mathrm{~b}$ & $6.2 \pm 0.6 \mathrm{a}$ \\
$0.5 \%$ & $8.1 \pm 0.7 \mathrm{a}$ & $5.4 \pm 0.8 \mathrm{a}$ & $4.6 \pm 1.1 \mathrm{~b}$ \\
$1.0 \%$ & $8.1 \pm 0.8 \mathrm{a}$ & $4.3 \pm 1.0 \mathrm{~b}$ & $5.8 \pm 0.4 \mathrm{a}$ \\
$2.5 \%$ & $8.1 \pm 1.1 \mathrm{a}$ & $5.8 \pm 0.6 \mathrm{a}$ & $4.3 \pm 1.0 \mathrm{~b}$ \\
$5.0 \%$ & $7.9 \pm 1.1 \mathrm{a}$ & $3.8 \pm 1.1 \mathrm{c}$ & $3.4 \pm 0.4 \mathrm{c}$ \\
$10.0 \%$ & $7.6 \pm 0.8 \mathrm{a}$ & $2.2 \pm 0.8 \mathrm{c}$ \\
\hline
\end{tabular}

Note: Different letters in the same column indicate significantly difference at the 0.05 level.

Compared to control, receptor plants had curly root and the color of its root becomes deep and dark, indicating that the allelochemicals from maize leaves aqueous extract inhibited the cell division of radicle and germ of receptor seedlings. In addition, we found that the inhibition effect of the potential allelochemicals in maize leaves leachate on receptor plant's root appeared more sensitive than that on receptor plant's shoot, which is consistent with previous reports (Meksawat and Pornprom, 2010; Sitthinoi et al., 2017). The reason is probably because of under the test conditions there was enough moisture in the Petri dishes, root growth of elongation was inhibited and the root became stout, which is advantageous to the absorption of moisture, so as to promoted the growth of seedlings or changed the material distribution between the seedlings and root of the receptor plant.

Allelopathy refers to the beneficial or harmful effects of one plant on another by the release of inhibitory substances from plants into the environment through root exudation, leaching and volatilization, and through the decomposition of plant residues. Allelopathy in agriculture is receiving considerable attention because of the allelochemicals that reduce the yields of crop plants due to phytotoxicity (Khalid et al., 2002; Inderjit and Duke, 2003; Weston and Duke, 2003; Gulzar et al., 2017), and this chemical substances is polymer, mainly compound with phenols and fatty acid, and exists in the soil-plant systems with ester key form ( $\mathrm{Li}$ et al., 2010c; Greer et al., 2014). A number of studies showed that allelopathy effects of receptor was depend on the concentrations of water extracts of organs from donor plants, different concentration has different effects, it has obviously concentration effect (Han et al., 2002; Ahmed et al., 2008; Siddiqui et al., 2009; Sitthinoi et al., 2017). In this study, with the concentration of the aqueous extract increased, the stimulating effects on the rate of seed germination, root length, shoot height and fresh weight of all the receptors gradually decreased, and even changed into inhibited. However, allelopathic potential would vary significantly at different growth stages and in various habitats. A previous study demonstrated significant differences in the type of allelochemical produced by rice, depending on the growth stage (Song et al., 2004), so allelopathy effects of water extracts of maize leaf on the three medicinal plants also need further more research work to do at other growth stage.

The study found that soluble sugar content and soluble protein content of all receptor seed which treat with low concentrations $(0.5 \%, 1.0 \%, 2.5 \%)$ water extracts of maize leaf were higher than those of control. There are reports that the content of soluble sugar of seed was increased when it under the adversity conditions, emergence of this phenomenon is not only due to that soluble sugar influence cell osmotic regulation function, and more important is that many soluble carbohydrates are the signal substance of plant adapt to the special environments, and it can adjust the defensive reaction of the plant (Yoshida et al., 2002). 
In addition, under the adversity conditions, amount of protein expression of plant was changed, and some specific protein was induced (Shen et al., 2003; Renaut et al., 2004), so the final protein content depends on the change of both. Soluble protein content of three medicinal plants seed which treat with low concentrations $(0.5 \%, 1.0 \%, 2.5 \%)$ water extracts of maize leaf were higher than that of other treatments, it is suggest that in allelochemicals' stress, plant may produce some specific protein to resist the adverse effect of the outside world, this finding is consistent with the results in grape (Li et al., 2010a). Some studies suggested that allelochemicals inhibits plant growth by reducing photosynthesis, interruption of dark respiration and ATP synthesis and disruption of amino acids metabolism (Hejl et al., 1993; Weir et al., 2004). In our experiment, the photosynthesis rate of three receptor plants showed different variable trends induced by leaves leachate. There was no significant difference in photosynthesis rate at all the tested concentration for Platycodon grandiflorum A.DC, but it decreased net photosynthesis rate of Salvia miltiorrhiza Bge compared with control, and in Scutellaria baicalensis Georgi the lower concentrations $(0.5 \%, 1.0 \%$, $2.5 \%)$ of leachates stimulated the net photosynthesis rate and higher concentrations $(5 \%, 10 \%)$ decreased the net photosynthesis rate. These results showed the positive and negative mechanisms of maize leaves leachate on various receptor plants. Similar results were also observed in medicinal plants under walnut leaves leachate ( $\mathrm{Li}$ et al., 2010b). However, tying laboratory experiments to field trials has proved to be one of the weakest links for understanding allelopathy as an important process in plant communities. There is no single bioassay that can demonstrate the occurrence of allelopathy, nor its conditional effects in a variable environment. Bioassays for allelopathy must consider abiotic and biotic environmental factors, and be linked to exudation rates, soil concentrations, and function in natural soil environments (Weidenhamer, 1996), so allelopathy effects of water extracts of maize leaf on the three medicinal plants must have further study.

The research area is located in the Shangluo Mountain area, and the regional economic development is very slow, and land natural resources also in short supply. In order to promote economic development and increasing the farmers' income, the local government encourage people to grow the Chinese herbal medical plants which have higher economy benefit than traditional crops. In the food crops and Chinese herbal medical plant intercropping system, the rainfall leaching phenomenon exists generally during the plant growth period, and the leaching content of crops may have influence on the sublayer herbal medical plant. In previous food crops-herbage compound system we pay more attention to it technology research, application of plant morphological structure, the use of collocation and nutrients complementary, but oversight the "allelopathy affection" factors, and finally bring negative impact to the composite system, and this problem also limits the theory of allelopathy to apply in the crops-herbage composite system. The ecological agriculture maintains diversity of plant species on the farm through various types of multiple cropping systems, such as mixed cropping, crop rotations etc., hence, allelopathy assumes great significance.
Allelopathy may be used to increase crop production through avoidance of negative impacts, exploitation of stimulatory effects, management and development of allelopathic crops and varieties to suppress pests (weeds, insects, nematodes, pathogens) and use of allelochemicals as pesticides and growth regulators.

\section{Conclusions}

In conclusion, the study of allelopathy effects of water extracts of maize leaf on Platycodon grandiflorum A.DC, Scutellaria baicalensis Georgi and Salvia miltiorrhiza Bge not only for provide some basis theory about how to establish and manage a complex system with the different traditional crops and Chinese traditional medical plants in the actual practice, but also has very important practical significance for food stability and economic development of the local government.

\section{Acknowledgements}

The authors are grateful to the Project of Natural Science Foundation of Shaanxi province (2014KJXX-79) and Project of Shangluo (SK2014-01-06).

\section{References}

Ahmed R, Hoque AR, Hossain MK (2008). Allelopathic effects of leaflitters of Eucalyptus camaldulensis on some forest and agricultural crops. Journal of Forestry Research 19(1):19-24.

Baziar MR, Farahvash F, Mirshekari B, Rashidi V (2014). Allelopathic effect of ryegrass (Lolium persicum) and wild mustard (Sinapis arvensis) on barley. Pakistan Journal of Botany 46(6):2069-2075.

Dorning M, Cipollini D (2006). Leaf and root extracts of the invasive shrub, Lonicera maackii, inhibit seed germination of three herbs with no autotoxic effects. PlantEcology 184(2):287-296.

Inderijt, Duke SO (2003). Ecophysiological aspects of allelopathy. Planta 217(4):529-539.

FabricantDS, Farnsworth NR (2001). The value of plants used in traditional medicine for drug discovery. Environmental Health Perspectives 109(Suppl 1):69-75.

Gao WW, Zhao YJ, Wang YP, Chen SL (2006). A review of research on sustainable use of medicinal plants cropland in China. Zhongguo ZhongYaoZaZhi31(20):1665-1669.

Greer MJ, Wilson GW, Hickman KR, Wilson SM (2014). Experimental evidence that invasive grasses use allelopathic biochemicals as a potential mechanism for invasion: chemical warfare in nature. Plant and Soil 385(1-2):165-179.

Gulzar A, Siddiqui MB (2017). Allelopathic effect of Calotropisprocera (Ait.) $\mathrm{R}$ Br. on growth and antioxidant activity of Brassica oleracea var. botytiti. Journal of the Saudi Society of Agricultural Sciences 16(4):375-382.

Han L, Shen Q, Ju H, Yan S, Yan F (2002). Allelopathy of the aqueous extracts of above ground parts of soybean and the identification of the allelochemicals. ActaEcologicaSinica 22(9):1425-1432.

Hejl AA, Einhellig FA, Rasmussen JA (1993). Effects of juglone on growth, 
200

photosynthesis, and respiration. Journal of Chemical Ecology 19(3):559-568.

Hou YX, Song XY, Yin YL, Li YS, YangJS, Zheng JY (2016). Allelopathic effects of allelochemicals of Ginkgo biloba leaf on fusarium wilt (Fusarium oxysporum) of hot pepper. Allelopathy Journal 39(1):103114.

Jefferson LV, Pennacchio M (2003). Allelopathic effects of foliage extracts from four Chenopodiaceae species on seed germination. Journal of Arid Environments 55(2):275-285.

Khalid S, Ahmad T, Shad R (2002). Use of allelopathy in agriculture. Asian Journal of Plant Sciences 1(3):292-297.

Kohli RK, Batish D, Singh HP (1997). Allelopathy and its implications in agroecosystems. Journal of Crop Production 1(1):169-202.

Li K, Guo XW, Guo YS, Li CX, Xie HG, Hu XX, ... Sun YN (2010a). Allelopathy of grape root aqueous extracts. Yingyong Shengtai Xuebao 21(7):1779-1784.

Li Q, Cai J, Jiang Z, Zhang S (2010b). Allelopathic effects of walnut leaves leachate on seed germination, seedling growth of medicinal plants. Allelopathy Journal 26(2):235-242.

Li Z, Wang Q, Ruan X, Pan CD, Jiang DA (2010c). Phenolics and plant allelopathy.Molecules 15(12):8933-8952.

LiuX, Tian F, Tian Y, Wu Y, Dong F, Xu J,Zheng Y (2016). Isolation and identification of potential allelochemicals from aerial parts of avena fatua 1. and their allelopathic effect on wheat. Journal of Agricultural and Food Chemistry 64(18):3492-3500.

MachadoS (2007). Allelopathic potential of various plant species on downy brome: implications for weed control in wheat production. Agronomy Journal 99(1):127-132

Read SM,Northcote $\mathrm{DH}$ (1981). Minimization of variation in the response to different proteins of the Coomassie blue $\mathrm{G}$ dye-binding assay for protein. Analytical Biochemistry 116(1):53-64.

Renaut J, Lutts S, Hoffmann L, Hausman JF (2004). Responses of poplar to chillingtemperatures: proteomic and physiological aspects. Plant Biology 6(1):81-90.

Shen S, Jing Y, Kuang T (2003). Proteomics approach to identify woundresponse related proteins from rice leafsheath. Proteomics 3(4):527-535.
Siddiqui S, Yadav R, Yadav K, Wani FA, Meghvansi MK, Sharma S, Jabeen F (2009). Allelopathic potentialities of different concentration of aqueous leaf extracts of some arable trees on germination and radicle growth of Cicer arietinum Var. C-235. Global Journal of Molecular Sciences 4(2):91-95.

Singh HP, Batish DR, Kohli RK (2001). Allelopathy in agroecosystems: an overview.Journal ofCrop Production 4(2):141.

Sitthinoi P, Lertmongkol S, Chanprasert W, Vajrodaya S (2017). Allelopathic effects of jungle rice (Echinochloa colona (L.) Link) extract on seed germination and seedling growth of rice. Agriculture and Natural Resources 51(2):7478.

Song HK, Ahn JK, Ahmad A, Hahn SJ, Kim SH, Chung IM (2004). Identification of allelochemicals in rice root exudates at various phenological phases and their influence on barnyardgrass. Allelopathy Journal 13(2):173-188.

Vieira RF, Skorupa LA (1993). Brazilian medicinal plants gene bank. Acta Horticulturae 330(330):51-58.

Weidenhamer JD (1996). Distinguishing resource competition and chemical interference: overcoming the methodological impasse. Agronomy Journal 88(6):866-875.

Weir TL, Park SW, Vivanco JM (2004). Biochemical and physiological mechanisms mediated by allelochemicals. Current Opinion in Plant Biology 7(4):472-479.

Weston LA, Duke SO (2003). Weed and crop allelopathy. Critical Reviews in Plant Sciences 22(3-4):367-389.

Williamson GB, Richardson D (1988). Bioassays for allelopathy: measuring treatment responses with independent controls. Journal of Chemical Ecology 14(1):181-187.

Yoshida S, Ito M, Nishida I, Watanabe A (2002). Identification of a novel gene HYSI/CPRS that has a repressive role in the induction of leat senescence and pathogen-defence responses in Arabidopsis thaliana. Plant Journal 29(4):427-437.

Yuan H, Ma Q, Ye L, Piao G (2016). The traditional medicine and modern medicinefrom natural products. Molecules21(5):559. 